\title{
The Role of Physical Props in VR Climbing Environments
}

\author{
Peter Schulz \\ University of Bremen \\ Bremen, Germany \\ schulzp@uni-bremen.de
}

\author{
Dmitry Alexandrovsky \\ University of Bremen \\ Bremen, Germany \\ dimi@uni-bremen.de
}

\author{
Felix Putze \\ University of Bremen \\ Bremen, Germany \\ felix.putze@uni-bremen.de
}

\author{
Rainer Malaka \\ University of Bremen \\ Bremen, Germany \\ malaka@informatik.uni-bremen.de
}

\begin{abstract}
Dealing with fear of falling is a challenge in sport climbing. Virtual reality (VR) research suggests that using physical and reality-based interaction increases the presence in VR. In this paper, we present a study that investigates the influence of physical props on presence, stress and anxiety in a VR climbing environment involving whole body movement. To help climbers overcoming fear of falling, we compared three different conditions: Climbing in reality at $10 \mathrm{~m}$ height, physical climbing in VR (with props attached to the climbing wall) and virtual climbing in VR using game controllers. From subjective reports and biosignals, our results show that climbing with props in VR increases the anxiety and sense of realism in VR for sport climbing. This suggests that VR in combination with physical props are an effective simulation setup to induce the sense of height.
\end{abstract}

\section{CCS CONCEPTS}

- Human-centered computing $\rightarrow$ Virtual reality; Haptic devices; Empirical studies in HCI.

\section{KEYWORDS}

Virtual reality; Climbing; Biosensors; Fear of Falling; Physical props; Presence.
Permission to make digital or hard copies of all or part of this work for personal or classroom use is granted without fee provided that copies are not made or distributed for profit or commercial advantage and that copies bear this notice and the full citation on the first page. Copyrights for components of this work owned by others than the author(s) must be honored. Abstracting with credit is permitted. To copy otherwise, or republish, to post on servers or to redistribute to lists, requires prior specific permission and/or a fee. Request permissions from permissions@acm.org. CHI 2019, May 4-9, 2019, Glasgow, Scotland UK

(c) 2019 Copyright held by the owner/author(s). Publication rights licensed to ACM.

ACM ISBN 978-1-4503-5970-2/19/05 ..\$15.00

https://doi.org/10.1145/3290605.3300413
Johannes Schöning

University of Bremen

Bremen, Germany

schoening@uni-bremen.de

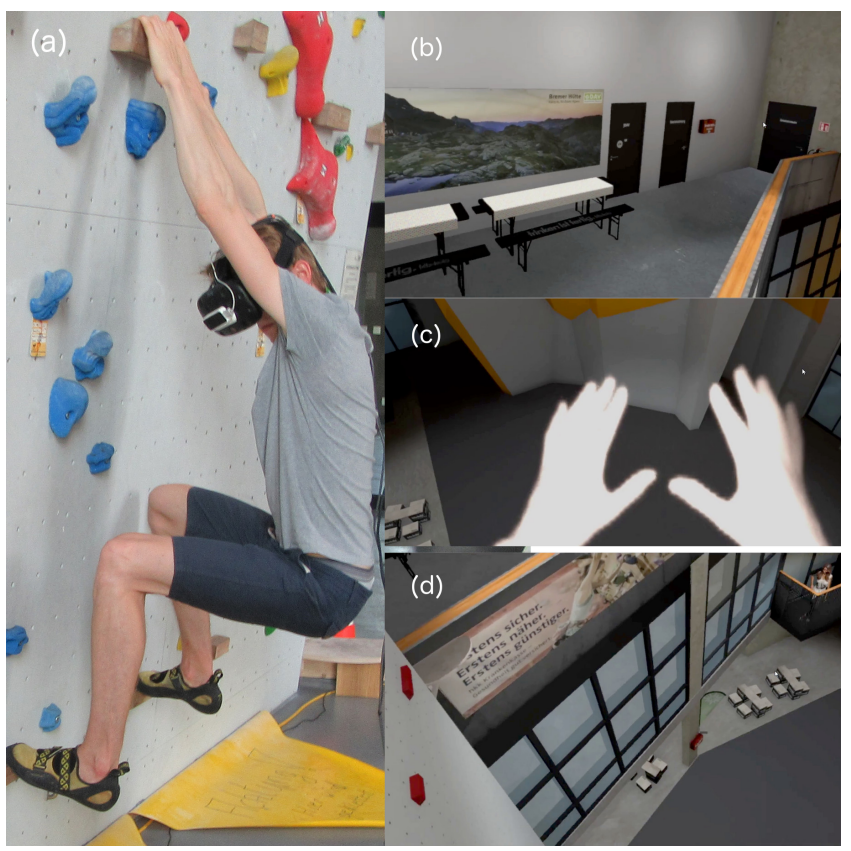

Figure 1: (a) A subject is climbing horizontally on the wall while wearing a head-mounted display and virtually climbing at a height of $10 \mathrm{~m}$. (b)-(d) Example views of the VR scene from the user's perspective.

\section{ACM Reference Format:}

Peter Schulz, Dmitry Alexandrovsky, Felix Putze, Rainer Malaka, and Johannes Schöning. 2019. The Role of Physical Props in VR Climbing Environments. In CHI Conference on Human Factors in Computing Systems Proceedings (CHI 2019), May 4-9, 2019, Glasgow, Scotland UK. ACM, New York, NY, USA, 13 pages. https://doi.org/ $10.1145 / 3290605.3300413$ 


\section{INTRODUCTION \& MOTIVATION}

In sport climbing, it is important to overcome the fear of falling as it holds back climbing athletes by impeding movements [28] and effects on the athlete's performance [26]. Climbers learn to overcome their fear of falling by building confidence in training and, for instance, by habituation through controlled falling [48]. Beyond the fear of falling, sport climbing is also associated with general height-induced anxiety, which in its pathological form is acrophobia. One way of treating this condition is exposure therapy, the "golden standard" in the field of psychotherapy [59].

Starting in the mid-1990s, scientists began experimenting with virtual reality exposure therapy (VRET), which gave them more control over the grading of exposure and reduced the inhibition threshold for a therapy [59]. VRET uses headmounted displays (HMDs), spatial audio and e.g., data gloves to create a high sense of presence for the subjects. Presence is considered the defining factor for VRET to work [15, 27]. In their study, Emmelkamp et al. showed that exposure to heights in virtual reality (VR) achieves the same effects as in-vivo therapy [17], a result that has been reproduced multiple times since then $[36,55,59]$. In a large scale study with 100 acrophobia patients over the course of two weeks, Freeman et al. [21] showed significant improvement in overcoming fear of height after few weeks of treatment with an automated VRET in comparison to regular in-vivo therapy. Besides presence, immersion is an important measure in VR. From an extensive content analysis of 83 studies on presence and immersion, Cummings and Bailenson conclude that the immersion provided by increased levels of user tracking and the quality of the mediated virtual environment has a medium effect on improving the sense of presence in the virtual environment (VE) [13]. For sport climbers and industrial climbers, a VR training environment allows climbing training to counter fear of falling even in times of recovery or when a real climbing environment is not available.

In this paper, we report on the design of a VR climbing environment that supports overcoming the fear of falling. Based on traditional training of handling fear of falling in sport climbing and VRET from psychology, we investigate to what extent realistic physical sensation is necessary to create an immersive climbing experience which comes with a natural anxiety induced by a feeling of height. We conducted an experiment in VR to compare the manifestation of anxiety (measured directly and indirectly through induced stress) and presence at subjective and physiological levels. We compared climbing, a complex whole body movement, using props (hand- and footholds) with controller-based climbing simulation and observed higher subjective anxiety and presence for props.

\section{RELATED WORK}

In this section, we discuss how anxiety is related to sport climbing and present related work on physiological measurement of anxiety and presence as a foundation for our study design. Furthermore, we discuss VR, augmented reality (AR) and mixed realtity (MR) in climbing scenarios.

Sport climbing is a superset of various different activities. The most prominent activities are lead climbing, top-rope climbing and bouldering. When doing a lead climb, a climber is attaching the rope with quickdraws to the wall to secure him while ascending the route. When climbing a route toprope, the climber is secured by the rope through an anchor at the top of the route. Bouldering characterizes a climbing activity in low heights (typically below $6 \mathrm{~m}$ ) without any belaying equipment.

\section{Arousal, Fear, Anxiety and Stress in Sport Climbing}

Breckner describes fear as an essential factor in all levels of sport, from mass sport to elite sport [7]. He further describes, that reasons for fear depend on the personality and quotes Allmer and Schulz, who supposed that there are different trigger situations: (i) risk (ii) limitation, handicap or failure (while feeling the pressure to succeed) (iii) insecurity (when confronted with unknown situations significant for the subject) (iv) competition [1]. For climbers, it is unpleasant to face an imminent risk of falling, yet they are motivated to venture falling and mastering the hardest parts of the route ("conquer the crux"). At the same time, it is linked to physiological arousal [43, 44] with typical somatic symptoms like uneasiness, pale skin, cold hands and sweating. Also, increased muscle tensions, raised respiratory rate $(\mathrm{RR})$ and heart rate (HR), elevated urinary frequency and adrenaline/no-adrenalin level have been observed [6]. Tietjens also considers specific behaviors such as fleeing and avoidance as typical fear reactions [71].

Anxiety is triggered by threats that are perceived as uncontrollable or unavoidable $[45,64]$. In his thesis on anxiety in extreme mountaineering, Breckner [7] refers to stress as a relational concept [41] where stress is the result of an individual evaluating a situation defined by the environment. This evaluation includes inner requirements (self-imposed goals) as well as outer requirements (e.g., trainer-imposed goals). The individual evaluates the impact of the environment for its well-being and the necessary resources or skills for success.

Since the beginning of the 20th century, research has been concerned with the effects of anxiety on performance in sports. Early experimental studies led to the hypothesis that there is a point of anxiety-infused activation resulting in peak performance. Later this idea was replaced by a theory of individual zones of optimal functioning (IZOF) that 
Ruiz and colleagues verified in several studies [62]. Based on Masters et al. [49] and Liao et al. [46], Bertle conducted a study to examine the stress reactions to an impending fall of climbing protection and height above ground [3]. The study investigated two conditions of height (low/high) and two climbing styles: leading and top-rope. The results of Bertle's study show significant cognitive and somatic anxiety reactions in a high (fall) condition compared to a low (fall) condition. Further, Bertle found that well-trained subconscious routines and movements are processed more consciously under stress [3]. In several experiments with climbers Pijpers et al. measured effects of anxiety induced by fear of falling while climbing. In their setups, the participants traversed (i.e., climb horizontally) an identical route at different heights above ground, while being belayed in top rope. All studies showed an increase of anxiety-related effects in the high condition and evidence for anxiety-related reduction in performance [56-58]. Hardy and Hutchinson found in their studies with climbers that less anxious climbers perform better than highly anxious climbers. The authors assume that self-confident subjects and skillful climbers are less likely to be impacted by anxiety [26].

\section{Physiological Measures of Anxiety}

Bertle [3] summarizes multiple studies with skydivers and base jumpers. Inexperienced skydivers show a raised heart rate $(\mathrm{HR})$, resperatory rate $(\mathrm{RR})$ and electrodermal activity (EDA) throughout a flight which do not decrease until landing [20,74]. Breivik et al. [8] could not corroborate Eysenck's and Calvo's Arousal Theory nor could they validate Fenz and Epsteins [18] consistent correlations of HR to subjective feelings among experienced jumpers [20]. However, they showed that experience (number of jumps) is correlated negatively to arousal [8], an observation Hardy and Hutchinson [26] later made again for climbers. Roth et al. found similar results that showed rising physiological measures and anxiety self-ratings for parachutists in anticipation of a jump-independent of the level of expertise, only at higher levels for novices [61].

Judging from the body of work examined, we based our study on the assumption that anxiety in sport climbing is a multidimensional phenomenon. We focused mainly on one dimension: fear of falling, as it is verified to have a hindering effect on performance $[18,26,58]$. Regarding terminology, this paper is primarily concerned with anxiety, and not with fear or phobia. Therefore, we use the terms fear of falling and anxiety of falling synonymously.

\section{VR-Treatment for Stress and Anxiety}

Acrophobia is an abnormal fear of heights which in turn is related to the fear of falling [3]. Therefore, research looking into a climbers' fear of falling in VR would be of particular interest, in context of a more general question on how VR is suited for the treatment of fear in specific situations. However, no such work has been published so far, regarding acrophobia and its therapy using VRET. Several studies showed that VRET for acrophobia treatment is as effective as regular exposure therapy, producing the same fear of height in virtual environments as in-vivo [40, 53, 59]. Diemer et al. ran a controlled experiment to compare height reactions of phobics and non-phobics. Both groups showed similar physiological arousal when exposed to height [14]. This implicates that not only phobics but also participants comparable to those of other climbing-related studies listed above, show respective effects.

Since we use height above ground as a stressor, the perception of height in VR is of particular concern. The extent to which the (simulated) height works as a trigger depends on the effectiveness of VR and thereby the amount of presence it evokes in its users [51]. Meehan conducted three studies that investigated the influence different aspects of VR on presence. He looked at effects of multiple exposure, passive haptics and effect of frame rate on presence. In the passive haptics experiment, Meehan showed that a plywood ledge has an influence on presence, while participants were walking towards a virtual cliff [50]. Gandy et al. summarize several studies examining effects of varying levels of detail on presence and perception-with contradicting results [22]. On the one hand, Zimmons and Panter could not find significant differences in presence or subjective stress when running variations of "the pit" experiment [50], ranging from wireframe to radiosity [75]. However, Slater et al. found increased psycho-physiological measures, HR and skin conductivity (SC), for a higher level of realism (reflections and shadows) [68]. In alignment with Gandy et al. (2010), who summarized that a "[virtual] environment does not have to be visually perfect to make users feel present or capable of a motor task", we recreated a degree of realism comparable to that of "the pit" experiment by Meehan et al. [51].

\section{Augmenting Climbing with Technology}

Byrne and Mueller investigated the motives for climbing and how digital systems can support sport climbing [10]. The authors identified five key motivational themes: risk, challenge, social engagement, beauty of nature and reliving the experience. These motivational themes offer guidelines when designing augmented climbing experiences. There is also a significant line of work that investigates augmented climbing. From our literature examination, we observed several recurring motives: immersive experience, training and monitoring. 
Immersive climbing setups. There are VR games that provide a virtual climbing experience. For example, The Climb (http://www.theclimbgame.com) employs a head-mounted display (HMD) and allows players to climb in mountain environments using VR controllers. Similarly, Kosmalla et al. [39] showed a VR climbing environment which employed a 3D scanned climbing wall and hand tracking using Leap Motion. To train motor skills, Kajastila and colleagues designed Augmented Climbing-a bouldering setup which employs projection on the climbing wall and full-body motion tracking $[34,35]$. The setup provides augmented feedback on the climbing wall to enhance sport training. From three user studies the authors conclude that augmented climbing is an effective tool for engagement, movement diversity and also lets climbers forgetting about fear of height. Liljedahl and colleagues developed Digiwall, an interactive climbing wall with sensors, light and sound feedback. The authors promote a set of applications, which include training, play and sound design [47]. BetaCube by Wiehr et al. implements a self-calibrating camera which employs a wall projection of life-size video replays and holds highlighting for route creation [73]. Kosmalla et al. build on BetaCube and designed an AR climbing system to teach novices climbing movements. Their application employs a recording mode using a KINECT for the trainer and three types of video playback using AR-goggles and a projection on the climbing wall. Participants performed various tasks with different modalities of video guidance. The results indicate that a hybrid visualization suits best to fit all requirements of a climbing training environment [37]. Venga! is a setup that allows for fully augmented climbing in VR [70]. In their setup, the authors 3D-scanned a climbing wall and applied hand and foot tracking to create an immersive climbing experience in VR.

Wearables for climbing. Mencarini et al. defined a design space of wearables for climbing as tools for augmentation and communication [52]. They identified that in sport climbing either the walls can be augmented or climbers can be equipped with wearable devices. The authors suggest instead of eliminating negative emotions, the training environment should help climbers dealing with them and promote to design wearables that support the communication of fear in sport climbing. Based on results of an online survey and a follow up user study, Kosmalla et al. [38] found that sound is suited best as a communication channel for a wrist worn wearable in climbing. ClimbAX is a wristband sensor which was designed to monitor the climbers' performance. From accelerometer data, the wearable extracts various performance metrics (e.g., climbing episodes and hold transitions) and provides climbing statistics [42]. To guide beginners in improving their climbing technique in real-time while climbing,

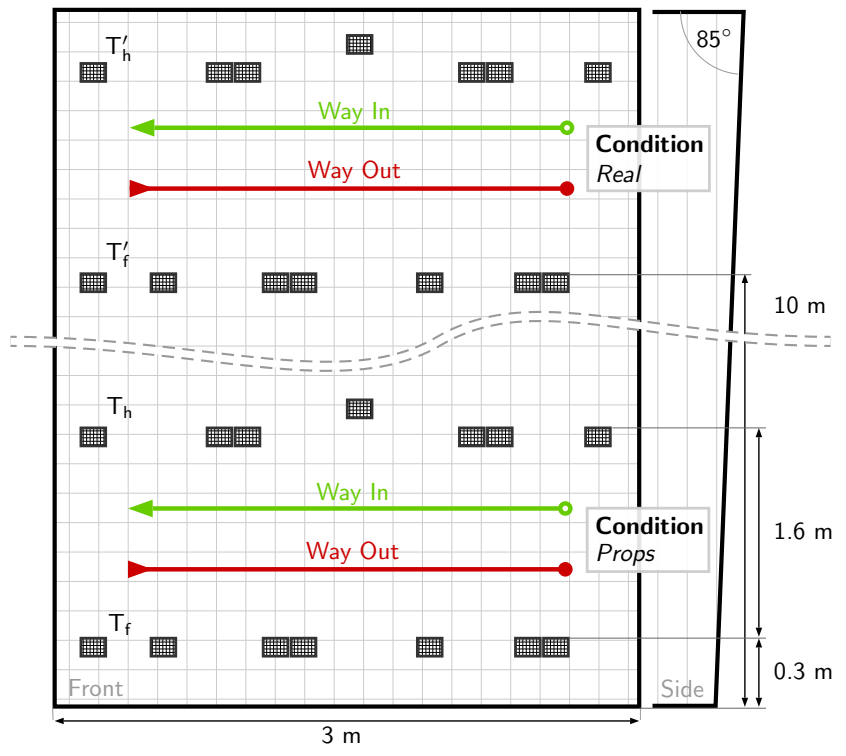

Figure 2: Schematic view of the climbing routes. Two identical climbing routes at different heights, each consisting of 14 hand and footholds. $T_{h}$ and $T_{f}$ mark the holds at the turning point.

Feeken et al. developed a pressure sensitive insole with vibrotactile feedback [19]. Tonoli et al. employed an acceleration sensor which is integrated into the harness to identify and monitor falling in rock climbing using a Kalman filter [72]. Similarly, Boulanger et al. applied machine learning to classify climbing activities from multiple accelerometers [5].

Most of the literature we examined applies technology to support the climbers' performance. However, training of fear of falling is rarely investigated in the literature. In our work, we build on the climbing setups that employs VR to investigate the effect of physical interaction on presence and anxiety in climbing. Therefore, our study aims at closing the gap and brings together two areas of research: effects of height-induced anxiety while climbing and anxiety while moving through VR.

\section{STUDY}

In our study, we focus on the level of immersion-induced presence, required to provoke fear of falling in VR. Therefore, we create three different conditions: real physical climbing in $10 \mathrm{~m}$ height $\left(C_{\text {real }}\right)$, virtual reality climbing with real props $\left(C_{\text {props }}\right)$ at virtual height of $10 \mathrm{~m}$ but physically $20 \mathrm{~cm}$ above the ground and an entirely virtual climbing simulation with game controllers $\left(C_{\text {ctrl }}\right)$ at virtual height of $10 \mathrm{~m}$ while standing on the ground. We used physiological measurements (heart rate and skin conductivity) together with questionnaires asking for the subjective responses to compare the effect of three conditions. In alignment with Meehan [50], 


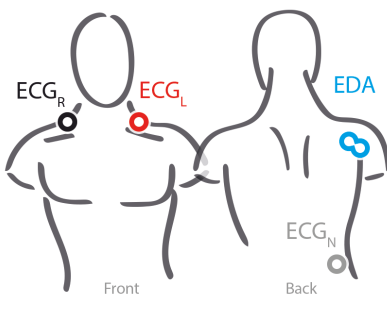

(a)

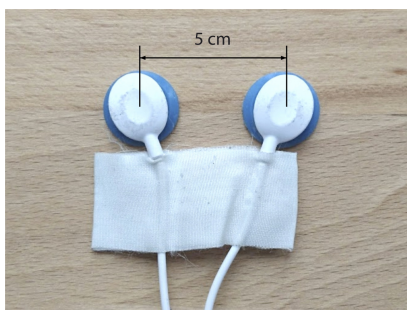

(b)
Figure 3: (a) Schematic view of a torso with the placements of the electrocardiography (ECG) and EDA electrodes. (b) EDA electrodes prepped with a piece of tape to keep them at a constant distance of $5 \mathrm{~cm}$.

who observed a positive effect of props on presence, we derive the following hypotheses:

Hypothesis $\left(H_{P}\right)$ : Presence $\left(D_{p}\right)$ is measurably higher for climbers in VR when using props $\left(C_{\text {props }}\right)$ compared to a entirely virtual condition $\left(C_{\text {ctrl }}\right)$.

Hypothesis $\left(H_{A}\right)$ : Anxiety $\left(D_{a}\right)$ (measured directly and indirectly in form of stress) is higher for climbers in VR when using props $\left(C_{\text {props }}\right)$ compared to a purely virtual condition $\left(C_{\text {ctrl }}\right)$.

Our study design has two independent variables: props or game controllers and real or virtual vision resulting in three conditions. We aimed to examine their effect on the following dependent variables: physical exertion, anxiety and presence. Since anxiety is highly subjective and varies between participants, we chose a within-subject experimental study to test our hypothesis. The order of the conditions was randomized using a Latin Square [23].

For the study, we developed a multimodal VR climbing setup that employs foot and hand tracking and allows for real climbing with a HMD.

\section{Measurements}

In alignment with the studies by Slater [66, 67] we measured stress and anxiety as indicators of presence. Our primary stress and anxiety measures were heart rate variabilty (HRV) $[11,31]$ and skin conductivity response (SCR) $[9,50]$. We recorded the physiological data using Bitalino Board Kit 2018. As shown in Figure 3, we placed the ECG electrodes at the collarbone and the EDA sensors on the shoulder of the participants. Additionally, presence was measured using the widespread Igroup Presence Questionnaire (IPQ) on the spatial presence (sp), involvement (inv) and experienced realism (real) subscales [63].

Meehan [50] suggests HR, RR and EDA as indicators for presence. Regarding sport climbers, Hardy and Hutchinson [26] reckon that those signals-when elevated-may be interpreted as signs of somatic anxiety, too. However, HR and RR cannot be described as unitary functions of arousal, because they are also dependent on physical activity [12]. Hence, they can only be interpreted as indicators for somatic anxiety when comparing conditions with a similar level of physical activity. In our setup, these are only $C_{\text {real }}$ and $C_{\text {props }}$. As a control variable for the level of movement, we also asked the subjects to give a rating of perceived exertion (RPE) on a labeled visual analog scale (VAS) from 6 to 20, developed by [4].

To measure the severity of acrophobia, we employed the visual height intolerance (vHI) questionnaire [30]. This questionnaire has an opening question followed by eight items and results in a severity score (vHISS) between 0 (low) and 13 (high). With two additional questions, a diagnosis of acrophobia can be established. To meter the trait anxiety of subjects, we used the State Trait Anxiety Inventory (STAI) [24]. This inventory consists of ten items and results in a score between 20 (low) and 80 (high), which indicates the participants' tendency of responding to situations perceived as thrilling with an elevation of state anxiety. After each condition, we also tested the manifestation of anxiety at the level of subjective experience through a VAS-also called anxiety thermometer (AT) [29]. This is a quick and validated alternative to more comprehensive tools such as subjective units of discomfort scale (SUDS), or competitive state anxiety inventory 2 (CSAI2) [57]. It is a continuous scale ranging from 0 (not anxious at all) to 10 (extremely anxious), displayed as a box of $10 \mathrm{~cm}$ length in which participants place a mark to indicate their level of anxiety [29].

\section{Procedure and Tasks}

Our experiment procedure included the following steps: (i) briefing (ii) put on climbing harness (iii) fit with HR, RR, and EDA electrodes (iv) initial rest $\left(C_{0}\right)$ and upfront questionnaires (v) randomized order of $C_{\text {real }}, C_{\text {props }}$ and $C_{\text {ctrl }}$ conditions (vi) debriefing. After each condition, the participants had time to recuperate while filling in the Igroup Presence Questionnaire (IPQ) and AT questionnaires.

The primary task for all conditions was traversing a climbing wall, from a start point to a return point and back. The subjects were only belayed in condition $C_{\text {real }}$ utilizing an auto-belay-device. To ensure that the participants are aware of their exposition to height, we introduced secondary tasks: (i) before climbing, throw a ball down to the ground and read out the number displayed next to where the ball dropped (ii) while resting at the return point, look down and read out numbers shown on the ground floor. 


\section{Climbing Routes}

We conducted our experiment in a local climbing gym with a wall that fulfills the specifications for one lane of an International Federation of Sport Climbing (IFSC) speed climbing wall. The traversal route is angled at $5^{\circ}$ along its entire length and is easily accessible on the ground floor and from a balcony at $10 \mathrm{~m}$ height. Figure 2 depicts the final route layout for condition $C_{\text {real }}(10 \mathrm{~m})$ and its twin at the bottom of the wall for condition $C_{\text {props }}$. Both routes have a launching platform made of plywood, each serving as the start and end point for the climbing task. The routes had a difficulty of $4+$ on the International Climbing and Mountaineering Federation (UIAA) scale; a difficulty level that is suitable for beginners. By letting our participants climb the same horizontal route at a constant elevation in each condition, we maintained comparability with Pijpers et al. [58] and kept height (our main trigger for anxiety) at a constant level.

We modeled the climbing gym in VR, using an already existing architectural 3D model as a foundation to match the virtual environment and the climbing wall. Further, we textured and added lighting as well as some interior such as tables and fire extinguishers. By resembling the original premises with such details as furniture, we created points of reference in support of a sense for scale and height. The climbing routes, sketched in Figure 2, required for the VR conditions $C_{\text {props }}$ and $C_{\text {ctrl }}$ were also added. We utilized $\mathrm{Au}-$ todesk Maya for modelling and Unity $3 \mathrm{D}$ as a game engine to create an interactive experience. We used an HTC VIVE system for tracking the head, two controllers and two additional trackers for the feet. Lastly, for tracking the hands, we employed a Leap Motion hand tracking device mounted on the VIVE headset. The entire setup is illustrated in Figure 1. For our setup, we implemented hand visuals as a masked, tinted overlay of the infrared image coming from the Leap Motion camera using a custom shader (Figure $4 \mathrm{~b}$ ).

To match the static grips with their corresponding twins in the virtual environment, we implemented a semi-automated calibration with two VIVE trackers. For calibration, we placed two VIVE trackers on the climbing route and registered the components. From the stored locations, we computed the required transformations to align the props.

Footwork and technique are essential in climbing [65]. Therefore, a precise foot tracking was implemented using VIVE trackers. For the foot tracking, we fixed a VIVE tracker to a rubber band and attached it to the user's heel (see Figure 4c).

To avoid a break of immersion and for security reasons, we did not model a rope and didn't belay the participants in the VR physical condition $\left(C_{\text {props }}\right)$. As the subjects climbed only a few meters above ground a (belayed) rope could swing back against the wall and injure the participant in case of a fall. Furthermore, an entirely virtual rope without a physical rope present would break the immersion if the subjects tried to grab it and also lead to a fall.

\section{Participants}

We followed Guo et al.'s guidelines [25] and used GLIMMPSE to calculate an appropriate sample size. We assumed an effect size of Cohen's d between 0.7 and 1.2 at a confidence level of $\alpha=0.05$ and a power $>0.8$ similar to climbing-related experiments by Hardy and Hutchinson [26]. Our calculations required a sample size between 11 and 30 participants to show significant effects.

A total of 28 participants (13 female), mean age 30.7 years $(\mathrm{SD}=10.6)$, volunteered to participate in the experiment. The participants, for the greater part customers of the local climbing gym, were mainly lead climbers (23), but also top-rope climbers (4) and one boulderer.

The average UIAA climbing degree (level of difficulty) of the lead climbers was $6+( \pm 1$ degree $)$ and of the top-rope climbers 5+/6- ( \pm 1 degree). About three quarters of the participants climb at least once a week. 13 participants had never used a VR system prior to the experiment and 13 only once; the remaining two participants had used various systems frequently before. All subjects provided written informed consent.

We used the short version of the STAI [24] as a standard check to measure trait anxiety. The questionnaire consists of 10 items on a 8-point Likert-scale. The overall mean trait anxiety was $34.9(\mathrm{SD}=14.9)$. The results were comparable to the scores originally surveyed by Spielberg [69]. Hence, these results indicate that the participants had no extraordinary tendency to respond to situations perceived as threatening with an elevation in state anxiety [57].

To identify and eventually exclude participants who fulfill the psychiatric criteria of acrophobia, we asked them to answer the vHI questionnaire [30]. The vHI questionnaire was only presented to the 16 participants who affirmed the opening question; none of the users gave indications to suffer from acrophobia. The average severity score was $M=1.4$ $(\mathrm{SD}=0.16)$.

\section{RESULTS}

In this section, we report the results gathered from the physiological measurements and self-reports for the three conditions of our experiment. First, duration of climbing and the level of physical exertion is examined to ensure we only compare homogeneous conditions later on. Then, we continue with the outcomes for stress and anxiety and, finally, presence. Due to missing or corrupted data we excluded up to 7 participants for when we performed our analysis. We report the number of subjects, that were applied for each statistical test. 


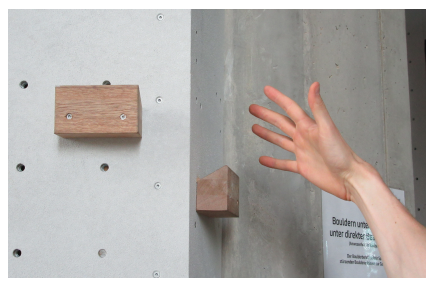

(a)

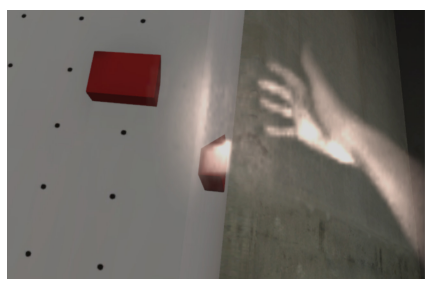

(b)

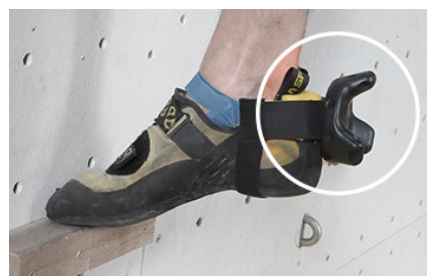

(c)

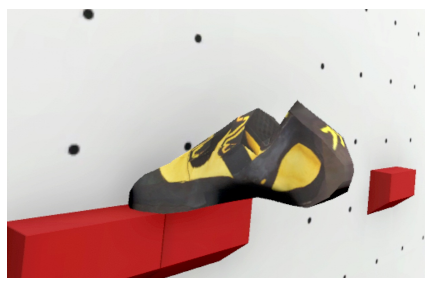

(d)

Figure 4: (a) Hand over a hand hold. (b) Screenshot of the resulting, masked infrared overlay. (c) Heel-mounted VIVE tracker. (d) Virtual representation of the foot in VR.

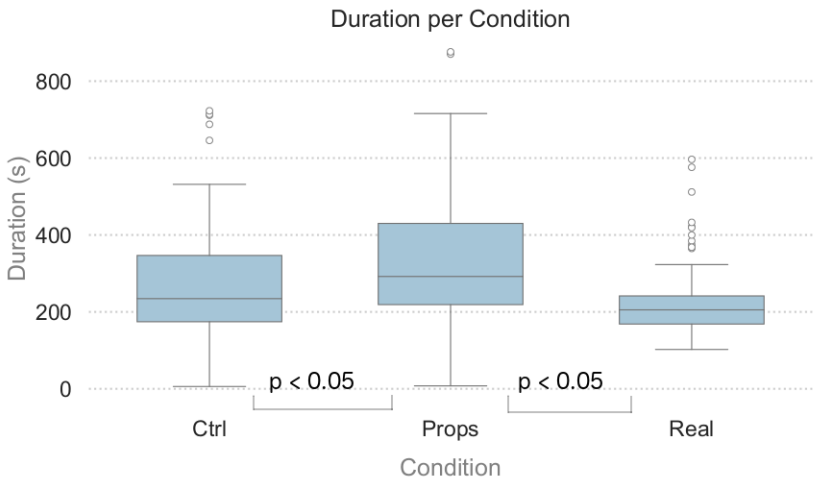

Figure 5: Duration per condition. The error bars indicate the first and fourth quartiles.

\section{Duration}

We conducted a repeated measures analysis of variance (ANOVA) to examine the effect of the condition on the time that participants took to complete the tasks. The analysis was performed with $n=23$. Regarding the duration per conditions (Figure 5), there was a significant effect: $\mathrm{F}(2,44)=9.092$, $\mathrm{p}<0.01$. The effect has an observed power of 0.966 with $\eta_{\mathrm{p}}^{2}=0.292$. A correction for sphericity was not necessary $\left(\chi^{2}(2)=0.872, \mathrm{p}=0.188\right)$. Pairwise Bonferroni tests showed significant differences between $C_{\text {real }}$ and $C_{\text {props }}(\mathrm{p}<0.01), C_{\text {real }}$ and $C_{\mathrm{ctrl}}(\mathrm{p}<0.05)$, but not between $C_{\text {props }}$ and $C_{\mathrm{ctrl}}(\mathrm{p}=0.575)$.

\section{Physical Exertion}

We recorded the vital signs HR and RR because they are indicators for physical exertion. HR was measured using an ECG in combination with a chest strap to obtain reference signal less prone to motion artifacts. We conducted a repeated measures ANOVA to examine the effect of the condition on HR for both sources. For ECG-based HR $(n=23)$, Mauchly's test of sphericity indicated that the assumption of sphericity had not been violated, $\chi^{2}(2)=5.866, p=0.320$. There was a significant effect of condition on the HR: $F(3,63)=22.502, p<0.01$. The effect has an observed power of 1.0 with $\eta_{\mathrm{p}}^{2}=0.517$. For

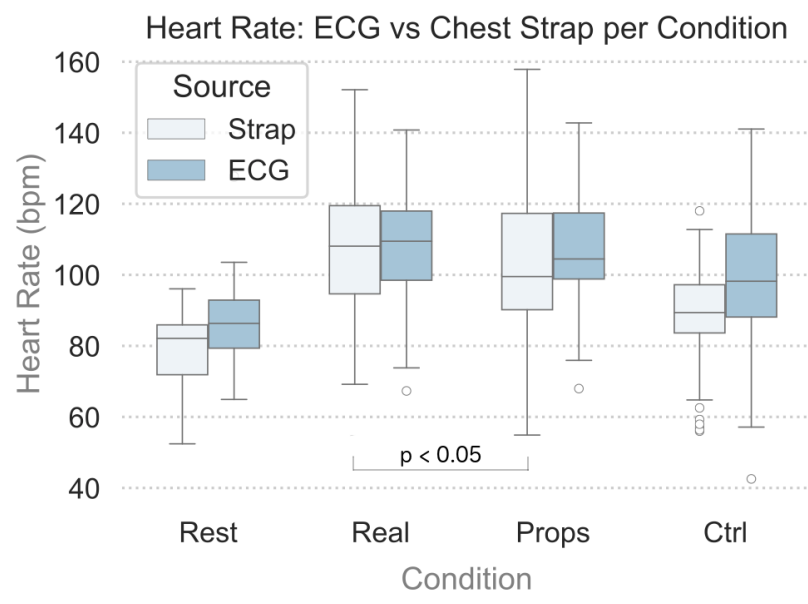

Figure 6: Average heart rate (HR) measured before $\left(C_{0}\right)$ and during the conditions $\left(C_{\text {real }}, C_{\text {props }}\right.$, and $\left.C_{\text {ctrl }}\right)$ using ECG and a chest strap. The error bars indicate the first and fourth quartiles.

the recordings from the chest strap $(n=22)$, Mauchly's test of sphericity indicated a violation of sphericity, $\chi^{2}(2)=12.653$, $\mathrm{p}<0.05$ and therefore, a Greenhouse-Geisser correction was used. There was a significant effect of condition on the HR: $F(2.192,46.035)=92.877, p<0.01$. The effect has an observed power of 1.0 with $\eta_{\mathrm{p}}^{2}=0.816$. Pairwise Bonferroni tests revealed a significant difference in HR between $C_{\text {real }}$ and $C_{\text {props }}(\mathrm{p}<0.05)$ for both sources. The results are shown in Figure 6.

Since the RPE yields discrete, ordinal results, we used a Friedman test to examine the effect of condition on selfreported physical exertion. There was a significant effect of condition on RPE, $\chi^{2}=23.234, \mathrm{p}<0.01$. A pairwise Wilcoxon signed ranks test showed a significant difference for $C_{\text {real }}$ and $C_{\text {props }}(\mathrm{Z}=-2.517, \mathrm{p}=0.012), C_{\text {real }}$ and $C_{\text {ctrl }}(\mathrm{Z}=-2.34, \mathrm{p}=0.019)$ and $C_{\text {props }}$ and $C_{\mathrm{ctrl}}(\mathrm{Z}=-3.817, \mathrm{p}<0.01)$. The results are shown in Figure 7. 


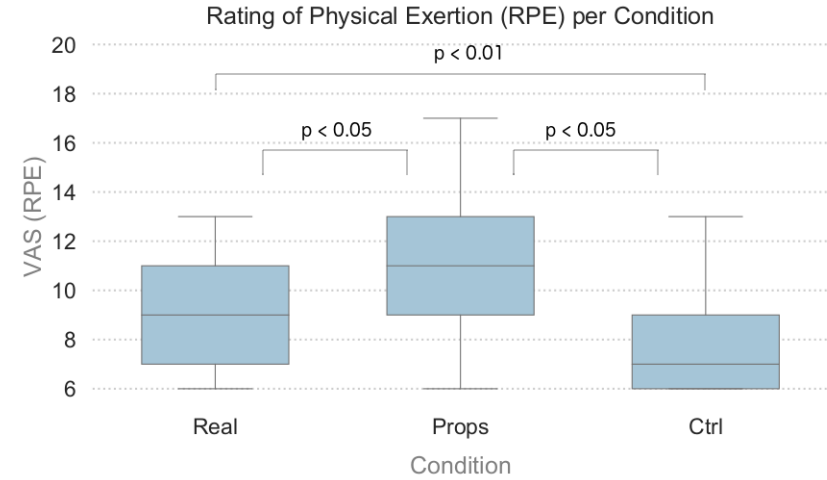

Figure 7: Average rating of perceived exertion (RPE) as reported via visual analog scale (VAS) after each condition ( $C_{\text {real }}, C_{\text {props }}$, and $\left.C_{\text {ctrl }}\right)$ on a scale from 6 to 20. The error bars indicate the first and fourth quartiles.

\section{Stress and Anxiety}

For the analysis of anxiety, we used the ECG signal and derived the mean R-R interval (mRRI) from it as a measure of HRV. Further, we measured EDA and derived the SCR-level from it (Figure 8). To examine the effect of the condition on each measure, we conducted a repeated measures ANOVA. For mRRI ( $\mathrm{n}=21)$, Mauchly's test of sphericity indicated a violation of sphericity, $\chi^{2}(2)=16.401, \mathrm{p}<0.05$ and therefore, a Greenhouse-Geisser correction was used. There was a significant effect of condition on mRRI: $\mathrm{F}(2.036,40.719)=4.331$, $\mathrm{p}<0.05$. The effect has an observed power of 0.725 with $\eta_{\mathrm{p}}^{2}=0.178$. A pairwise Bonferroni test revealed only a significant difference between $C_{0}$ and $C_{\text {props }}(\mathrm{p}<0.01)$.

To examine SC, we looked at two of the non-specific responses (NSR): response-count and conductivity level [60]. The first was calculated from the rolling average of detected peaks within a $20 \mathrm{~s}$ time-frame. Neither the response count nor the level did show any patterns. Hence, unlike the HRV, we could not find any significant differences between the conditions for the EDA signals.

In contrast to RPE, the VAS anxiety thermometer (AT) uses a continuous scale (Figure 9). We could conduct a repeated measures ANOVA without correction $\left(\chi^{2}(2)=0.692\right.$, $\mathrm{p}=0.708)$. There was a significant effect of condition on selfreported anxiety, $\mathrm{F}(2,44)=5.364, \mathrm{p}<0.05$. The effect has an observed power of 0.815 with $\eta_{\mathrm{p}}^{2}=0.195$. A pairwise Bonferroni test of the conditions revealed that the mean AT response for $C_{\text {props }}$ is significantly higher than for $C_{\text {ctrl }}(\mathrm{p}<0.01)$.

\section{Presence}

In the VR conditions $C_{\text {props }}$ and $C_{\text {ctrl }}$, the participants rated their sense of presence through an IPQ questionnaire $(n=27)$; the results can be seen in Figure 10. To examine the effect of the condition on presence scores, we conducted paired

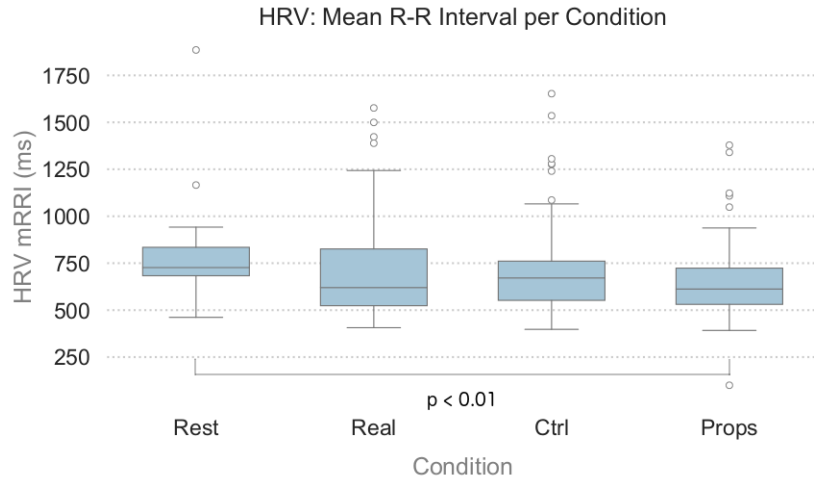

Figure 8: Mean R-R interval (mRRI) measured before $\left(C_{0}\right)$ and during the conditions $\left(C_{\text {real }}, C_{\text {props }}\right.$, and $\left.C_{\text {ctrl }}\right)$ based on ECG. The error bars indicate the first and fourth quartiles.

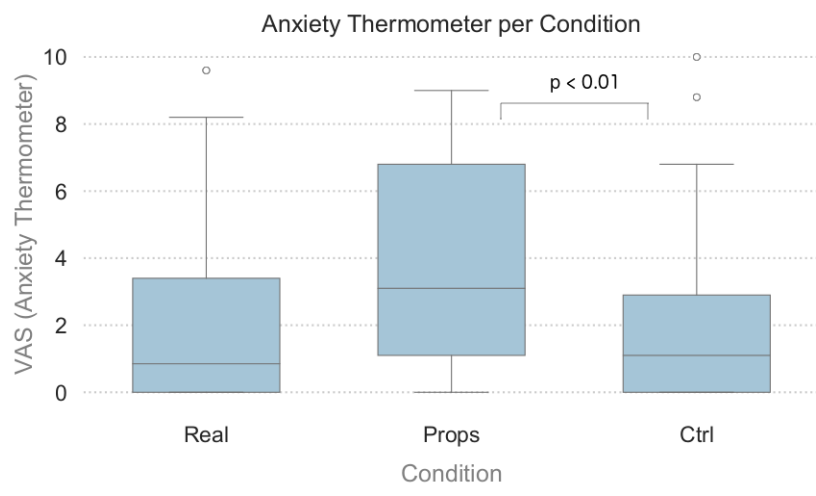

Figure 9: Average anxiety as reported via visual analog scale (VAS) after each condition $\left(C_{\text {real }}, C_{\text {props }}\right.$, and $\left.C_{\text {ctrl }}\right)$ on a scale from 0 to 10. The error bars indicate the first and fourth quartiles.

$\mathrm{t}$-tests. There only was a significant effect of the condition on realness scale (REAL) with $\mathrm{t}(26)=2.621, \mathrm{p}=0.014$. The effect has an observed power of 0.714 with $\eta_{\mathrm{p}}^{2}=0.209$. As suggested by [50], we also examined the rolling average of the HRusing a window of two respiration cycles-with no significant differences between the conditions.

The authors of the IPQ offer a database with results from multiple studies [32]. This dataset includes 37 records for experiments with 3D graphics displayed via HMD. Considering these, we found higher scores than those in the database on all scales. However, the differences were significant only for spatial awareness (SP) and realness (REAL) in condition $C_{\text {props }}\left(\delta_{\mathrm{SP}}=1.007, \mathrm{p}<0.01 ; \delta_{\mathrm{REAL}}=1.596, \mathrm{p}<0.01\right)$ and $C_{\text {ctrl }}\left(\delta_{\mathrm{SP}}=1, \mathrm{p}<0.01 ; \delta_{\mathrm{REAL}}=1.328, \mathrm{p}<0.01\right)$. 


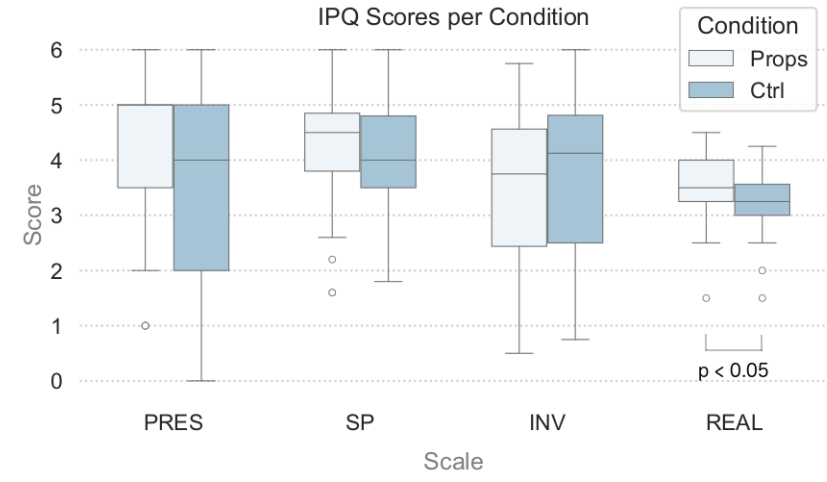

Figure 10: IPQ scores for the conditions $C_{\text {props }}$ and $C_{\text {ctrl }}$ on the scales general presence (PRES), spatial awareness (SP), involvement (INV) and realness (REAL). The error bars indicate the first and fourth quartiles.

\section{Qualitative Feedback}

After each run, we asked the subjects to comment on what they had just experienced. Here is a list of statements ordered by frequency: "It felt like being up there [on the high platform]" ( $C_{\text {props }}, 6$ times), "Climbing [in VR] felt more realistic [than using the controllers]" ( $C_{\text {ctrl }}, 6$ times), "The scene was very realistic" ( $C_{\text {props }}, 5$ times), "My feet were off a bit" ( $C_{\text {props }}, 4$ times), "I was not sure if I can trust the [VR] technology" ( $C_{\text {props }}, 3$ times), "I was more anxious, because I was not fixed to a rope [in VR]" $\left(C_{\text {props }}\right.$, twice), "Tracking was lost" ( $C_{\text {props }}$, twice), "I had a good feeling [when standing on the high platform]" ( $C_{\text {props }}$, once), "I could not see my hands, now and then" ( $C_{\text {props }}$, once), "I didn't feel like being up there [on the high platform] at all" ( $C_{\text {props }}$, once).

\section{DISCUSSION}

Our findings confirm the positive effect of props on presence [50], in particular for a VR sport climbing environment in which the participants performed complex whole body movements. As expected, both climbing conditions $C_{\text {real }}$ and $C_{\text {props }}$ were equally exerting. That is fully supported by HR and partially by RPE since the latter shows significantly higher scores for $C_{\text {real }}$ and $C_{\text {props }}$, compared to $C_{\text {ctrl }}$. We hypothesize, a VR sport climbing environment is a useful tool to train climbing situation, e.g., to overcome fear of falling. This is also supported by the self-reports of our participants, as the IPQ scale for realness showed a higher score for climbing with props compared to climbing with controllers.

Regarding $H_{A}$, we assumed anxiety is a consequence of the increased realness, measured on multiple scales: HRV, SCR and AT. The AT score $(\mathrm{M}=2.43, \mathrm{SD}=2.87)$ for real climbing $\left(C_{\text {real }}\right)$ was consistent with that reported by Pijpers et al. [56]. Further, in alignment with our hypothesis $H_{A}$, AT was significantly higher for $C_{\text {props }}$ than $C_{\text {ctrl }}$, although we could not find evidence in the physical measurements. For HRV, only mRRI was significantly lower in $C_{\text {props }}$ compared to $C_{0}$ (initial resting), i.e., there is no significant difference between the climbing conditions.

In contrast to HR, the RPE scores are higher in $C_{\text {props }}$ than in $C_{\text {real }}$. That difference may be attributed to increased anxiety in VR (not necessarily climbing-related) as observed by Hardy and Hutchinson [26]. One subject (ID=4), who reported slight offsets of tracking in $C_{\text {props }}$, mentioned that this experience was similar to climbing on brittle rock faces outside the climbing gym, which requires extra care and focus. The levels of exertions we demanded from our subjects were lower than those of Pijpers et al. [58]. In their experiment, they measured HRs ranging from $133 \mathrm{bpm}$ to $176 \mathrm{bpm}$ compared to $98 \mathrm{bpm}$ to $108 \mathrm{bpm}$ in our study.

From the qualitative feedback, we identified some noticeable glitches and occasional tracking issues. Our participants reported that particularly in a climbing scenario, a precise tracking is needed as, e.g., the foot placement is a crucial task in the climbing process.

\section{LIMITATIONS \& CHALLENGES}

Most of our participants reported high immersion and enjoyment during the VR climbing condition. However, experiments in complex VR climbing environments are challenging since climbers are used to very accurate hand and foot placements on the holds. Therefore, a precise and robust tracking of the climber's movements is required to avoid a break of immersion. Nevertheless, most comments were positive, and we collected only a few statements regarding glitches and mismatch problems. This assure us that our prototype worked very well and provided a sufficient trust in our setup. Also, the reports on high immersion indicate a small influence of the glitches.

For security reasons and to avoid a break of immersion, we deliberately decided not to show a virtual belay rope in the VR conditions $\left(C_{\text {props }}, C_{\text {ctrl }}\right)$. This potentially affects the comparability between the two physical climbing conditions ( $C_{\text {real }}$ and $\left.C_{\text {props }}\right)$. Nevertheless, we argue that only two subjects mentioned a missing rope in $C_{\text {props }}$ and the IPQ scores are above average, indicating that the presence of the rope has a minor effect on the overall experience and therefore, all three conditions are comparable.

Surprisingly, the SCRs measures, response-count and conductivity level, appeared to be utterly unaffected by the conditions. There are several possible reasons for this: First, we only looked at non-specific response (NSR) and not a specific event like $[9,33]$. Since the majority of our subjects climbs regularly, they may be accustomed to height. Second, the EDA electrodes on the shoulder could be affected by the climbing movements. Therefore, we recommend further research towards physiological measures of anxiety during 
complex physical activity such as climbing and encourage the development of sensors that are suited for complex whole body movements.

\section{CONCLUSION \& FUTURE WORK}

We conducted an experiment to investigate whether realistic physical sensations are necessary to create an immersive climbing experience (a complex whole body movement), which often comes with a natural anxiety induced by a feeling of height. We applied multiple measuring instruments, including objective bio-signal measures as well as subjective self-reports. This multimodal analysis showed a comprehensive picture of the experience which would not be captured with one of the instruments only. Our results are in alignment with earlier work by Insko [33] and Meehan [50], who also found increased self-reported and measured presence when using props. We extended the related work as climbing is a "complex whole-body task" [56]. Thereby, we showed that climbing free solo in VR results in increased stress and anxiety as well as presence. Hence, we were able to reproduce height-induced anxiety in VR, as described by $[26,57]$ for real climbing, and therefore our VR climbing environment could be a safe and effective training environment for sport climbing. In the future, we aim to evaluate the VR climbing environment in training with professional sport climbers over a longer time period to get insights how such a technology can be incorporated into an effective training schedule.

In this paper, we tested novel approaches for interaction mechanics throughout this experiment, which could be refined in future work. On the one hand, the heel-mounted trackers helped to work around loss-of-tracking-issues, but, on the other hand, they turned out to be sensitive to shocks and faulty calibration. Further, by employing a combination of video-overlay and tracked hands, based on the Leap Motion system, we could create a realistic representation of hands that allowed precise grasping and could compensate for the occasionally incorrectly visualized feet.

Similar to the findings of Muender et al. [54], our results show a strong connection between physical activity in VR and tactile sensation. When designing training environments, it is valuable to identify which components of the setup are most effective. We conclude that physical props can substantially increase the degree of realism and significantly strengthen the experienced presence. We argue that a VR setup that employs full body interaction and simple physical props can be used for safe and effective training environments. These findings support theories on embodied interaction $[2,16]$ and are of particular interest for designing immersive VR experiences and VR-based training applications.

\section{ACKNOWLEDGMENTS}

We thank the DAV climbing hall Bremen for their support and the opportunity to conduct the study in their facilities. This project has received partly funding by the German Federal Ministry of Education and Research in the grant program "Erfahrbares Lernen" (experienceable learning) and by the Volkswagen Foundation through a Lichtenberg Professorship.

\section{REFERENCES}

[1] Henning Allmer and Norbert Schulz (Eds.). 1998. 'No Risk-No Fun'Zur Psychologischen Erklärung von Extrem-Und Risikosportarten (in German Only). Erlebnissport-Erlebnis Sport. Brennpunkte der Sportwissenschaft. St. Augustin: Academia Verlag (1998), 60-90.

[2] Alissa N. Antle, Greg Corness, and Milena Droumeva. 2009. What the Body Knows: Exploring the Benefits of Embodied Metaphors in Hybrid Physical Digital Environments. Interacting with Computers 21, 1-2 (Jan. 2009), 66-75. DOI : http://dx.doi.org/10/fwh2sb

[3] Pirmin Bertle. 2014. Effekte der Sturzhöhe, der absoluten Höhe zum Boden und des Sicherungsstils auf psychologische, psychophysiologische und motorische Stressreaktionen von Kletterern. (in german only). Master Thesis. University of Fribourg, Switzerland.

[4] Gunnar Borg. 1982. Psychophysical Bases of Perceived Exertion. Medicine \& Science in Sports \& Exercise 14, 5 (1982), 377. DOI : http: //dx.doi.org/10/bnwtpk

[5] J. Boulanger, L. Seifert, R. Hérault, and J. Coeurjolly. 2016. Automatic Sensor-Based Detection and Classification of Climbing Activities. IEEE Sensors fournal 16, 3 (Feb. 2016), 742-749. DOI : http://dx.doi.org/10/ gd6gq4

[6] Ralf Brand. 2010. Sportpsychologie (in german only). Springer.

[7] Mirko Breckner. 2013. Der Umgang mit Angst im Extremsport: Eine Studie mit Bergsteigern des Expeditionskaders des Deutschen Alpenvereins (in german only). Master Thesis. University of Freiburg, Germany.

[8] Gunnar Breivik, Walton T. Roth, and Per Erik Jørgensen. 1998. Personality, Psychological States and Heart Rate in Novice and Expert Parachutists. Personality and Individual Differences 25, 2 (Aug. 1998), 365-380. DOI : http://dx.doi.org/10/cnh39d

[9] Anne-Marie Brouwer and Maarten Hogervorst. 2014. A New Paradigm to Induce Mental Stress: The Sing-a-Song Stress Test (SSST). Frontiers in Neuroscience 8 (July 2014), 224. DOI : http://dx.doi.org/10/gd3vxc

[10] Richard Byrne and Florian 'Floyd' Mueller. 2014. Designing Digital Climbing Experiences through Understanding Rock Climbing Motivation. In Entertainment Computing - ICEC 2014, Yusuf Pisan, Nikitas M. Sgouros, and Tim Marsh (Eds.). Vol. 8770. Springer, Germany, 92-99. DOI : http://dx.doi.org/10.1007/978-3-662-45212-7_12

[11] R. Castaldo, P. Melillo, U. Bracale, M. Caserta, M. Triassi, and L. Pecchia. 2015. Acute Mental Stress Assessment via Short Term HRV Analysis in Healthy Adults: A Systematic Review with Meta-Analysis. Biomedical Signal Processing and Control 18 (April 2015), 370-377. DOI : http://dx. doi.org/10/gd3vxb

[12] Rodney J Croft, Craig J Gonsalvez, Joanne Gander, Lisa Lechem, and Robert J Barry. 2004. Differential Relations between Heart Rate and Skin Conductance, and Public Speaking Anxiety. Fournal of Behavior Therapy and Experimental Psychiatry 35, 3 (Sept. 2004), 259-271. DOI : http://dx.doi.org/10/ck6kf6

[13] James J. Cummings and Jeremy N. Bailenson. 2016. How Immersive Is Enough? A Meta-Analysis of the Effect of Immersive Technology on User Presence. Media Psychology 19, 2 (April 2016), 272-309. DOI : http://dx.doi.org/10/gd3zd4

[14] Julia Diemer, Nora Lohkamp, Andreas Mühlberger, and Peter 
Zwanzger. 2016. Fear and Physiological Arousal during a Virtual Height Challenge-Effects in Patients with Acrophobia and Healthy Controls. Fournal of Anxiety Disorders 37 (Jan. 2016), 30-39. DOI : http://dx.doi.org/10.1016/j.janxdis.2015.10.007

[15] H. Q. Dinh, N. Walker, L. F. Hodges, Chang Song, and A. Kobayashi. 1999. Evaluating the Importance of Multi-Sensory Input on Memory and the Sense of Presence in Virtual Environments. In Proceedings IEEE Virtual Reality (Cat. No. 99CB36316). 222-228. DOI : http://dx.doi. org/10.1109/VR.1999.756955

[16] Paul Dourish. 2004. Where the Action Is: The Foundations of Embodied Interaction. MIT Press.

[17] Paul M. G. Emmelkamp, Mary Bruynzeel, Leonie Drost, and Charles A. P. G van der Mast. 2001. Virtual Reality Treatment in Acrophobia: A Comparison with Exposure in Vivo. CyberPsychology \& Behavior 4, 3 (June 2001), 335-339. DOI : http://dx.doi.org/10.1089/ 109493101300210222

[18] Michael W. Eysenck and Manuel G. Calvo. 1992. Anxiety and Performance: The Processing Efficiency Theory. Cognition and Emotion 6, 6 (Nov. 1992), 409-434. DOI: http://dx.doi.org/10.1080/ 02699939208409696

[19] Corinna Feeken, Merlin Wasmann, Wilko Heuten, Dag Ennenga, Heiko Müller, and Susanne Boll. 2016. ClimbingAssist: Direct Vibro-Tactile Feedback on Climbing Technique. In Proceedings of the 2016 ACM International foint Conference on Pervasive and Ubiquitous Computing Adjunct - UbiComp '16. ACM Press, Heidelberg, Germany, 57-60. DOI : http://dx.doi.org/10.1145/2968219.2971417

[20] Walter D. Fenz, Ph D, Seymour Epstein, and Ph D. 1967. Gradients of Physiological Arousal in Parachutists as a Function of Approaching Jump. Psychosomatic Medicine (1967), 33-51. DOI : http://dx.doi.org/ 10/gd3vxd

[21] Daniel Freeman, Polly Haselton, Jason Freeman, Bernhard Spanlang, Sameer Kishore, Emily Albery, Megan Denne, Poppy Brown, Mel Slater, and Alecia Nickless. 2018. Automated Psychological Therapy Using Immersive Virtual Reality for Treatment of Fear of Heights: A Single-Blind, Parallel-Group, Randomised Controlled Trial. The Lancet Psychiatry 5, 8 (Aug. 2018), 625-632. DOI : http://dx.doi.org/10/gd2h5n

[22] M. Gandy, R. Catrambone, B. MacIntyre, C. Alvarez, E. Eiriksdottir, M. Hilimire, B. Davidson, and A. C. McLaughlin. 2010. Experiences with an AR Evaluation Test Bed: Presence, Performance, and Physiological Measurement. In 2010 IEEE International Symposium on Mixed and Augmented Reality. 127-136. DOI : http://dx.doi.org/10.1109/ISMAR. 2010.5643560

[23] Seymour Geisser. 1961. The Latin Square As a Repeated Measurements Design. In Proceedings of the Fourth Berkeley Symposium on Mathematical Statistics and Probability, Volume 4: Contributions to Biology and Problems of Medicine. The Regents of the University of California

[24] Jürgen Grimm. 2009. State-Trait-Anxiety Inventory by Spielberger German long and short version. MF-Working Paper 2009/02 Methodenforum University of Viena, Austria (Feb. 2009).

[25] Yi Guo, Henrietta L Logan, Deborah H Glueck, and Keith E Muller. 2013. Selecting a Sample Size for Studies with Repeated Measures. BMC Medical Research Methodology 13 (July 2013), 100. DOI : http: //dx.doi.org/10.1186/1471-2288-13-100

[26] Lew Hardy and Andrew Hutchinson. 2007. Effects of Performance Anxiety on Effort and Performance in Rock Climbing: A Test of Processing Efficiency Theory. Anxiety, Stress, \& Coping 20, 2 (June 2007), 147-161. DOI : http://dx.doi.org/10.1080/10615800701217035

[27] Larry F. Hodges, Barbara O. Rothbaum, Rob Kooper, Dan Opdyke, Thomas Meyer, Johannes J. de Graaff, James S. Williford, and Max M. North. 1994. Presence as The Defining Factor in a VR Application: Virtual Reality Graded Exposure in the Treatment of Acrophobia. (1994).

[28] Eric Hörst. 2017. Managing the Fear of Falling. https://trainingforclimbing.com/overcoming-the-fear-of-falling/. (2017).

[29] I. L. D. Houtman and F. C. Bakker. 1989. The Anxiety Thermometer: A Validation Study. Fournal of Personality Assessment 53, 3 (Sept. 1989), 575-582. DOI : http://dx.doi.org/10.1207/s15327752jpa5303_14

[30] Doreen Huppert, Eva Grill, and Thomas Brandt. 2017. A New Questionnaire for Estimating the Severity of Visual Height Intolerance and Acrophobia by a Metric Interval Scale. Frontiers in Neurology 8 (June 2017). DOI: http://dx.doi.org/10/gcz66m

[31] Esa Hynynen, Niilo Konttinen, and Heikki Rusko. 2009. Heart Rate Variability and Stress Hormones in Novice and Experienced Parachutists Anticipating a Jump. Aviation, Space, and Environmental Medicine 80, 11 (Nov. 2009), 976-980.

[32] igroup.org project consortium. 2016. IPQ Database. http://www.igroup.org/pq/ipq/data.php. (2016).

[33] Brent Edward Insko. 2001. Passive Haptics Significantly Enhances Virtual Environments. Ph.D. Dissertation. The University of North Carolina at Chapel Hill, USA.

[34] Raine Kajastila and Perttu Hämäläinen. 2014. Augmented Climbing: Interacting with Projected Graphics on a Climbing Wall. In Proceedings of the Extended Abstracts of the 32Nd Annual ACM Conference on Human Factors in Computing Systems (CHI EA '14). ACM Press, Toronto, Ontario, Canada, 1279-1284. DOI : http://dx.doi.org/10.1145/2559206. 2581139

[35] Raine Kajastila, Leo Holsti, and Perttu Hämäläinen. 2016. The Augmented Climbing Wall: High-Exertion Proximity Interaction on a Wall-Sized Interactive Surface. In Proceedings of the 2016 CHI Conference on Human Factors in Computing Systems - CHI '16. ACM Press, Santa Clara, California, USA, 758-769. DOI : http://dx.doi.org/10.1145/ 2858036.2858450

[36] E. Klinger, S. Bouchard, P. Légeron, S. Roy, F. Lauer, I. Chemin, and P. Nugues. 2005. Virtual Reality Therapy Versus Cognitive Behavior Therapy for Social Phobia: A Preliminary Controlled Study. CyberPsychology \& Behavior 8, 1 (Feb. 2005), 76-88. DOI : http://dx.doi.org/10. 1089/cpb.2005.8.76

[37] Felix Kosmalla, Florian Daiber, Frederik Wiehr, and Antonio Krüger. 2017. ClimbVis: Investigating In-Situ Visualizations for Understanding Climbing Movements by Demonstration. In Proceedings of the Interactive Surfaces and Spaces on ZZZ - ISS '17. ACM Press, Brighton, United Kingdom, 270-279. DOI : http://dx.doi.org/10.1145/3132272.3134119

[38] Felix Kosmalla, Frederik Wiehr, Florian Daiber, and Antonio Krüger. 2016. ClimbAware - Investigating Perception and Acceptance of Wearables in Rock Climbing. In Proceedings of the SIGCHI Conference on Human Factors in Computing Systems. ACM International Conference on Human Factors in Computing Systems (CHI-16), May 7-12, San fose,, CA, USA. ACM.

[39] Felix Kosmalla, André Zenner, Marco Speicher, Florian Daiber, Nico Herbig, and Antonio Krüger. 2017. Exploring Rock Climbing in Mixed Reality Environments. In Proceedings of the 2017 CHI Conference Extended Abstracts on Human Factors in Computing Systems (CHI EA '17). ACM, New York, NY, USA, 1787-1793. DOI : http://dx.doi.org/10.1145/ 3027063.3053110

[40] M Krijn, P. M. G Emmelkamp, R. P Olafsson, and R Biemond. 2004. Virtual Reality Exposure Therapy of Anxiety Disorders: A Review. Clinical Psychology Review 24, 3 (July 2004), 259-281. DOI : http://dx. doi.org/10.1016/j.cpr.2004.04.001

[41] Heinz Walter Krohne. 2010. Psychologie der Angst: Ein Lehrbuch (in german only) (1 ed.). Kohlhammer W., GmbH, Stuttgart, Germany.

[42] Cassim Ladha, Nils Y. Hammerla, Patrick Olivier, and Thomas Plötz. 2013. ClimbAX: Skill Assessment for Climbing Enthusiasts. In Proceedings of the 2013 ACM International foint Conference on Pervasive and Ubiquitous Computing (UbiComp '13). ACM, New York, NY, USA, 
235-244. DOI : http://dx.doi.org/10.1145/2493432.2493492

[43] Daniel M. Landers. 1980. The Arousal-Performance Relationship Revisited. Research Quarterly 51, 1 (March 1980), 77-90.

[44] Daniel M. Landers and S. M. Arent. 2001. Arousal-Performance Relationships. In Applied Sport Psychology: Personal Growth to Peak Performance (4th edition ed.), Jean M. Williams (Ed.). Mayfield Publishing, Mountain View, CA, 206-228.

[45] Michael Lewis. 2010. The Emergence of Human Emotions. In Handbook of Emotions, Michael Lewis, Jeannette M. Haviland-Jones, and Lisa Feldman Barrett (Eds.). Guilford Press, 304-319.

[46] Chu-Min Liao and Richard S.W. Masters. 2002. Self-Focused Attention and Performance Failure under Psychological Stress. Fournal of Sport and Exercise Psychology 24, 3 (Sept. 2002), 289-305. DOI : http://dx.doi. org/10/gd3vxk

[47] Mats Liljedahl, Stefan Lindberg, and Jan Berg. 2005. Digiwall: An Interactive Climbing Wall. In Proceedings of the 2005 ACM SIGCHI International Conference on Advances in Computer Entertainment Technology (ACE '05). ACM, New York, NY, USA, 225-228. DOI: http: //dx.doi.org/10.1145/1178477.1178513

[48] Matt Lloyd. 2014. The Mind Game: How to Overcome Fear. https://www.climbing.com/skills/the-mind-game-how-toovercome-fear/. (2014).

[49] Richard Masters and Jon Maxwell. 2008. The Theory of Reinvestment. International Review of Sport and Exercise Psychology 1 (Sept. 2008), 160-183. DOI : http://dx.doi.org/10.1080/17509840802287218

[50] Michael Meehan. 2001. Physiological Reaction as an Objective Measure of Presence in Virtual Environments. Ph.D. Dissertation. University of North Carolina, USA.

[51] Michael Meehan, Brent Insko, Mary Whitton, and Frederick P. Brooks, Jr. 2002. Physiological Measures of Presence in Stressful Virtual Environments. In Proceedings of the 29th Annual Conference on Computer Graphics and Interactive Techniques. ACM, New York, NY, USA, 645652. DOI : http://dx.doi.org/10.1145/566570.566630

[52] Eleonora Mencarini, Chiara Leonardi, Antonella De Angeli, and Massimo Zancanaro. 2016. Design Opportunities for Wearable Devices in Learning to Climb. In Proceedings of the 9th Nordic Conference on Human-Computer Interaction - NordiCHI '16. ACM Press, Gothenburg, Sweden, 1-10. DOI: http://dx.doi.org/10.1145/2971485.2971509

[53] Katharina Meyerbröker and Paul M.G. Emmelkamp. 2010. Virtual Reality Exposure Therapy in Anxiety Disorders: A Systematic Review of Process-and-Outcome Studies. Depression and Anxiety 27, 10 (Oct. 2010), 933-944. DOI: http://dx.doi.org/10.1002/da.20734

[54] Thomas Muender, Anke V. Reinschluessel, Sean Drewes, Dirk Wenig, Tanja Döring, and Rainer Malaka. 2019. Does It Feel Real? Using Tangibles with Different Fidelities to Build and Explore Scenes in Virtual Reality. In Proceedings of the 2019 CHI Conference on Human Factors in Computing Systems - CHI '19. ACM, Glasgow, Scotland, 12. DOI : http://dx.doi.org/https://doi.org/10.1145/3290605.3300903

[55] Andreas Mühlberger, Georg Wiedemann, and Paul Pauli. 2003. Efficacy of a One-Session Virtual Reality Exposure Treatment for Fear of Flying Psychotherapy Research 13, 3 (July 2003), 323-336. DOI : http://dx.doi. org $/ 10.1093 / \mathrm{ptr} / \mathrm{kpg} 030$

[56] Jan R. Pijpers, Raôul R. D. Oudejans, and Frank C. Bakker. 2005. Anxiety-Induced Changes in Movement Behaviour during the Execution of a Complex Whole-Body Task. The Quarterly fournal of Experimental Psychology Section A 58, 3 (April 2005), 421-445. DOI: http://dx.doi.org/10.1080/02724980343000945

[57] Jan R. Pijpers, Raoul R. D. Oudejans, Frank C. Bakker, and Peter J. Beek. 2006. The Role of Anxiety in Perceiving and Realizing Affordances. Ecological Psychology 18, 3 (July 2006), 131-161. DOI: http://dx.doi. org/10.1207/s15326969eco1803_1

[58] Jan R. Pijpers, Raôul R. D. Oudejans, Floris Holsheimer, and Frank C.
Bakker. 2003. Anxiety-Performance Relationships in Climbing: A Process-Oriented Approach. Psychology of Sport and Exercise 4, 3 (July 2003), 283-304. DOI : http://dx.doi.org/10.1016/S1469-0292(02)00010-9

[59] Mark B. Powers and Paul M. G. Emmelkamp. 2008. Virtual Reality Exposure Therapy for Anxiety Disorders: A Meta-Analysis. Journal of Anxiety Disorders 22, 3 (April 2008), 561-569. DOI : http://dx.doi.org/ 10.1016/j.janxdis.2007.04.006

[60] Psychlab. $1999 . \quad$ Skin Conductivity Explained. http://www.psychlab.com/SC_explained.html. (1999).

[61] Walton T. Roth, Gunnar Breivik, Per Erik Jørgensen, and Stefan Hofmann. 1996. Activation in Novice and Expert Parachutists While Jumping. Psychophysiology 33, 1 (Jan. 1996), 63-72. DOI: http://dx.doi. org/10/fmjq5m

[62] Montse C. Ruiz, John S. Raglin, and Yuri L. Hanin. 2015. The Individual Zones of Optimal Functioning (IZOF) Model (1978-2014): Historical Overview of Its Development and Use. International fournal of Sport and Exercise Psychology 15, 1 (May 2015), 41-63. DOI:http://dx.doi. org $/ 10 /$ gd $3 \mathrm{vxm}$

[63] Thomas Schubert, Frank Friedmann, and Holger Regenbrecht. 2001. The Experience of Presence: Factor Analytic Insights. Presence: Teleoper. Virtual Environ. 10, 3 (June 2001), 266-281. DOI : http://dx.doi.org/10. 1162/105474601300343603

[64] Peter Schwenkmezger and Georg Steffgen. 1989. Anxiety and Motor Performance. Medicine and Sport Science 29 (1989), 78-99. DOI : http: //dx.doi.org/DOI:10.1159/isbn.978-3-318-03943-6

[65] Dave Sheldon. 2014. Training: 7 Simple Drills To Improve Footwork And Technique - Climbing Magazine. https://www.climbing.com/skills/training-7-simple-drills-toimprove-footwork-and-technique/. (June 2014).

[66] Mel Slater. 2004. How Colorful Was Your Day? Why Questionnaires Cannot Assess Presence in Virtual Environments. Presence: Teleoperators \& Virtual Environments 13, 4 (2004), 484-493. DOI: http://dx.doi.org/10/d7nqft

[67] Mel Slater. 2007. The Concept of Presence and Its Measurement. (July 2007).

[68] M. Slater, P. Khanna, J. Mortensen, and I. Yu. 2009. Visual Realism Enhances Realistic Response in an Immersive Virtual Environment. IEEE Computer Graphics and Applications 29, 3 (May 2009), 76-84. DOI : http://dx.doi.org/10.1109/MCG.2009.55

[69] Charles D. Spielberger. 1983. State-Trait Anxiety Inventory for Adults. (1983).

[70] Marcel Tiator, Christian Geiger, Bastian Dewitz, Ben Fischer, Laurin Gerhardt, David Nowottnik, and Hendrik Preu. 2018. Venga!: Climbing in Mixed Reality. In Proceedings of the First Superhuman Sports Design Challenge: First International Symposium on Amplifying Capabilities and Competing in Mixed Realities (SHS '18). ACM, New York, NY, USA, 9:1-9:8. DOI: http://dx.doi.org/10.1145/3210299.3210308

[71] Maike Tietjens. 2006. Handbuch Sportpsychologie (in german only) (1 ed.). Number 153 in Beiträge zur Lehre und Forschung im Sport. Hofmann-Verlag, Schorndorf.

[72] Andrea Tonoli, Renato Galluzzi, Enrico C Zenerino, and Diego Boero. 2016. Fall Identification in Rock Climbing Using Wearable Device. Proceedings of the Institution of Mechanical Engineers, Part P: fournal of Sports Engineering and Technology 230, 3 (Sept. 2016), 171-179. DOI: http://dx.doi.org/10/gd6hr5

[73] Frederik Wiehr, Felix Kosmalla, Florian Daiber, and Antonio Krüger. 2016. betaCube: Enhancing Training for Climbing by a Self-Calibrating Camera-Projection Unit. In Proceedings of the 2016 CHI Conference Extended Abstracts on Human Factors in Computing Systems (CHI EA '16). ACM, New York, NY, USA, 1998-2004. DOI : http://dx.doi.org/10. $1145 / 2851581.2892393$

[74] Tim Woodman, Michelle Huggins, Christine Le Scanff, and Nicolas 
Cazenave. 2009. Alexithymia Determines the Anxiety Experienced in Skydiving. Fournal of Affective Disorders 116, 1 (July 2009), 134-138. DOI : http://dx.doi.org/10/cv4h4b

[75] P. Zimmons and A. Panter. 2003. The Influence of Rendering Quality on Presence and Task Performance in a Virtual Environment. In Proceedings IEEE Virtual Reality. 293-294. DOI : http://dx.doi.org/10.1109/ VR.2003.1191170 